\title{
P03-019 - Anakinra for sweet syndrome treatment
}

\author{
G Passaro, L Cerrito, M Giovinale, A Marinaro, A Soriano, D Rigante, R Manna* \\ From 7th Congress of International Society of Systemic Auto-Inflammatory Diseases (ISSAID) \\ Lausanne, Switerland. 22-26 May 2013
}

\section{Introduction}

Sweet syndrome (SS) is a rare autoinflamamtory neutrophilic dermatosis, sometimes associated with hematologic malignancies. We describe two cases of SS related to hematologic diseases successfully treated with an interleukin-1 (IL-1) receptor antagonist (Anakinra).

\section{Case report}

1- A 72-year-old man with diagnosis of Relapsing Polychondritis and Myelodysplastic syndrome (MDS) was referred for a 4-yr history of recurrent fever $\left(37.5\right.$ to $\left.39^{\circ} \mathrm{C}\right)$ accompanied by sudden onset of cutaneous purple papules on the extremities and hypodermic painful nodules on the forehead and scalp. The patient suffered of autoimmune atrophic gastritis and severe metasteroidal osteoporosis, but also complained of recurrent auricular chondritis, recurrent conjunctival inflammation, hearing loss, aphonia, and itching. Blood tests revealed high C-reactive protein $(43.2 \mathrm{mg} / \mathrm{l})$, pancytopenia, $1 / 160$ titer of ANA, and elevated beta2microglobulin $(10.10 \mathrm{mg} / \mathrm{ml})$. A host of blood tests and broncho-alveolar lavage fluid were negative. Bone marrow (BM) biopsy confirmed MDS. Histopatological evaluation of papules demonstrated neutrophilic nodular dermatitis with karyorrhexis without vasculitis, consistent with SS.

2- A 43-year-old man, with a 3-yr history of fever, periodic bone pain, and presence of maculo-papular erythematous skin lesions came to our observation. Histological examination of skin lesions demonstrated a diffuse infiltrate, consisting predominantly of mature neutrophils located in the upper dermis, framed as SS. MRI of pelvis and spine showed multiple sclerotic vertebral bone lesions. BM biopsy did not detect tumor cells, but instead identified inflammatory cells with intense sclerosis and calcification. Diagnosis of Chronic Recurrent Multifocal

\footnotetext{
Periodic Fever Research Center, Catholic University of Sacred Heart, Rome, Italy
}

(c) 2013 Passaro et al; licensee BioMed Central Ltd. This is an Open Access article distributed under the terms of the Creative Commons Attribution License (http://creativecommons.org/licenses/by/2.0), which permits unrestricted use, distribution, and reproduction in
Osteomyellitis (CRMO) was established. Treatment with etoricoxib, colchicine, corticosteroid was only partially successful, whereas bisphosphonate and anti-TNF therapy were completely uneffective.

In both these patients Anakinra was administered (100 $\mathrm{mg} /$ day by daily subcutaneous injection), obtaining the suppression of neutrophylic-mediated dermatologic manifestations. In the first case we also observed fever spike reduction, whereas in the second one there was the complete remission of fever and bone pain.

\section{Discussion}

Pathogenesis of SS involves cytokines and chemokines, as granulocyte-macrophage colony-stimulating factor and interleukins (e.g, IL-1, IL-3, IL-6, and IL-8). The optimal effect of Anakinra in these cases supports the major contributing role of IL-1beta in the physio-pathogenetic process of SS. The choice of alternative strategies, as antiIL1beta therapy, is feasible in the absence of detectable infections to reduce adverse effects of long-term steroid therapy or in cases of insufficient response to conventional treatment.

\section{Competing interests}

None Declared.

Published: 8 November 2013

\section{References}

1. Diamantino Fda E, Raimundo PM, Fidalgo Al: "Sweet's Syndrome and relapsing polychondritis signal myelodysplastic syndrome.". Anais Brasileiros de Dermatologia 2011, 86(4):173-177.

2. Calistru AM, Lisboa C, Azevedo F: "Paraneoplastic relapsing polychondritis and Sweet syndrome coexisting in a patient with myelodysplasia.". Indian Journal of Dermatology, Venereology, and 3.Leprology 2011, 77(6):730.

3. Schilling F, Kessler S: Chronic recurrent multifocal osteomyelitis. Klin Padiatr 2001, 213(5):271-6.

doi:10.1186/1546-0096-11-S1-A217

Cite this article as: Passaro et al:: P03-019 - Anakinra for sweet

syndrome treatment. Pediatric Rheumatology 2013 11(Suppl 1):A217. any medium, provided the original work is properly cited.

() Biomed Central 